\title{
Digital image correlation at high temperatures for fatigue and phase transformation studies
}

Strain Analysis

20I4, Vol. 49(4) 204-2II

(C) IMechE 2013

Reprints and permissions:

sagepub.co.uk/journalsPermissions.nav

DOI: $10.1177 / 0309324713498737$

sdj.sagepub.com

(SAGE

\author{
Martin J Holzweissig', Pirabagini Kanagarajah' and Hans J Maier²
}

\begin{abstract}
In this study, digital image correlation was used for two widely different cases to assess the potential and the limitations of the technique for applications at high temperatures. Specifically, digital image correlation was employed in hightemperature low-cycle fatigue experiments in a nickel-based superalloy and in phase transformation experiments conducted on bainitic steel in order to shed light on the microstructural processes. Depending on the type of experiments, the microstructure was characterized prior to the experiments (fatigue) or after the experiments (phase transformation). In the fatigue experiments, it was found that the features dominating damage evolution were the dendrites resulting from the solidification of the cast material. In the phase transformation experiments, variant selection is active when stresses are superimposed during the phase transformation process, which resulted in the evolution of transformation plasticity strains. Thereby, mainly the bainite variants oriented along the [I0I], [20I] and [I2I] directions were observed to grow parallel to the loading axis, which in turn led to transformation plasticity strains. For validation of the digital image correlation data, average strains were calculated for the surface area probed and compared to strain values obtained by conventional extensometry. In all cases studied, the correlation was satisfactory, indicating that digital image correlation can provide for additional insight into processes active at the micro level.
\end{abstract}

\author{
Keywords \\ High-temperature, digital image correlation, fatigue, phase transformation, microstructure
}

Date received: 8 January 2013; accepted: 2 July 2013

\section{Introduction}

Digital image correlation (DIC) is already widely used as this technique provides for contactless measurements of local strains. ${ }^{1-9}$ One field of application is the inspection of components with a focus on extending service intervals and reduction of maintenance costs. Furthermore, monitoring the evolution of localized strain can shed light on various microstructure-related phenomena. In this context, DIC has emerged as a powerful tool as it can be employed to track the evolution of strain fields during in situ tests with high lateral resolution. At elevated temperatures, plastic strains typically evolve more rapidly, but at the same time DIC becomes more challenging. Previous studies have already demonstrated that it is possible to apply DIC at high temperatures, although the resolution was low in these studies. ${ }^{4-6}$ Additional insight can be obtained if DIC is combined with other high spatial resolution techniques such as electron backscatter diffraction (EBSD). However, to the best of the authors' knowledge these studies were limited to ambient temperatures so far. $3,7,8$

The current work was undertaken with the motivation of addressing this issue, and hence the article shows that a combination of DIC with EBSD offers the possibility of resolving processes active at the microstructural level at high temperatures.

For DIC experiments a stable speckle pattern for the correlation is required. Applying a stable spackle pattern constitutes a major challenge for experiments carried out at high temperatures as most of the spray

\footnotetext{
'Lehrstuhl für Werkstoffkunde (Materials Science), University of Paderborn, Paderborn, Germany

${ }^{2}$ Institut für Werkstoffkunde (Materials Science), Leibniz Universität Hannover, Garbsen, Germany

\section{Corresponding author:}

Martin J Holzweissig, Lehrstuhl für Werkstoffkunde (Materials Science), University of Paderborn, 33095 Paderborn, Germany. Email: martin.joachim.holzweissig@uni-paderborn.de
} 


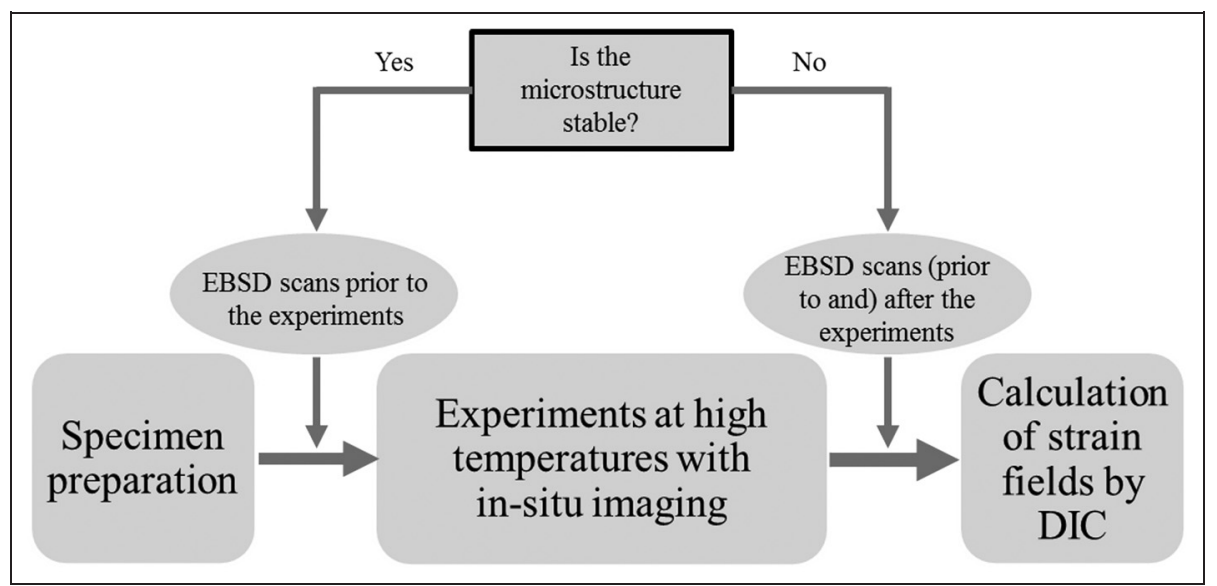

Figure I. Procedure for comparing strain fields calculated by DIC and microstructures visualized by EBSD scans.

painted spackle patterns will degrade during the experiment. Furthermore, changes in the surface properties due to oxidation processes can have an influence on the DIC results. Thus, in order to obtain reliable DIC results with high spatial resolution, a fine and stable spackle pattern, which is unaffected by oxidation, is required. ${ }^{4,5}$

Depending on the material behaviour and the type of the experiment, different approaches may be necessary. Thus, DIC was used for two widely different cases in this study in order to assess the potential and the limitations of the technique. Specifically, a nickel-based superalloy was used as this material provided a fairly stable microstructure throughout the experiment, whereas the low alloy steel studied is a system where a phase transformation takes place during the measurements.

For metallic materials exhibiting a stable microstructure under the conditions of the experiments, a characterization prior to the experiments by means of EBSD is sufficient (see Figure 1). This approach has the advantage that the preparation for the EBSD scan via electropolishing can induce a natural speckle pattern at the surface of the specimen that may already be suitable for DIC. In addition, if the electropolishing is conducted after the experiments a thin surface layer is removed, and thus, the correlation between DIC strains and the microstructure structure gets more difficult, especially when the relevant features are very small.

In metallic materials that exhibit a significant change in the microstructure during the high-temperature experiment, characterization by EBSD becomes more difficult. Cases in point are phase transformations, where the approach used here is to employ EBSD after the experiments (Figure 1). Clearly, this involves the problem that a thin layer of the surface is removed from the specimen making it challenging to achieve an accurate correlation between the strains measured by DIC and the EBSD orientation maps taken from the same area. ${ }^{9}$ However, it will be demonstrated that
EBSD and DIC data can still be recorded from the same area, and it is this combination of different techniques that helped to understand the dominating microstructural mechanisms.

\section{Experimental details}

For the high-temperature fatigue experiments, a nickelbased superalloy Inconel 939 was employed. The phase transformation experiments were conducted on a completely transforming $40 \mathrm{CrMnMoS} 86$ low alloy tool steel. The chemical compositions of the nickel-based alloy and the tool steel are summarized in Tables 1 and 2 , respectively.

The specimens were machined via electro-discharge machining. The specimens for the high-temperature fatigue experiments featured a gauge section with a width of $3 \mathrm{~mm}$ and a thickness of $1.5 \mathrm{~mm}$. In order to avoid necking of the specimens in the fatigue experiments, a bending support was placed around the gauge section of the specimens. Prior to the fatigue experiments, the gauge sections of the specimens were scanned by EBSD to reveal the microstructure. For the EBSD measurements, a scanning electron microscope (SEM) operating at a nominal voltage of $20 \mathrm{kV}$ was employed and the gauge sections of Inconel specimens were electropolished with a $5 \%$ perchloric acid solution under $20 \mathrm{~V}$ for $10 \mathrm{~s}$.

For the phase transformation experiments, the specimens had a gauge section with a width of $10 \mathrm{~mm}$ and a thickness of $1 \mathrm{~mm}$. The gauge sections of the specimens were polished prior to the experiments in order to provide for a well-defined starting surface condition. The EBSD measurements in the phase transformation experiments had to be conducted after the experiments as detailed below.

Both sets of experiments were conducted with servohydraulic test frames. In the fatigue experiments, the test frame was equipped with a high-frequency induction heater, a digital microscope taking images of the 
Table I. Chemical composition of the Inconel 939 studied.

\begin{tabular}{|c|c|c|c|c|c|}
\hline $\begin{array}{l}\text { Element } \\
\text { Mass content in \% }\end{array}$ & $\begin{array}{l}\mathrm{Cr} \\
23.7\end{array}$ & $\begin{array}{l}\text { Co } \\
19\end{array}$ & $\begin{array}{l}\mathrm{Ti} \\
3.4\end{array}$ & $\begin{array}{l}\mathrm{Nb} \\
2\end{array}$ & $\begin{array}{l}\mathrm{Al} \\
\mathrm{I} .6\end{array}$ \\
\hline Element & W & C & $\mathrm{Ta}$ & $\mathrm{Ni}$ & \\
\hline Mass content in \% & 2.3 & 0.15 & 1.4 & Balance & \\
\hline
\end{tabular}

The data shown represent the mean values obtained from various samples.

Table 2. Chemical composition of the $40 \mathrm{CrMnMoS8-6}$ steel studied.

\begin{tabular}{|c|c|c|c|c|c|}
\hline $\begin{array}{l}\text { Element } \\
\text { Mass content in \% }\end{array}$ & $\begin{array}{l}C \\
0.34\end{array}$ & $\begin{array}{l}\mathrm{Cr} \\
\mathrm{I} .73\end{array}$ & $\begin{array}{l}\mathrm{Mn} \\
\mathrm{I} .43\end{array}$ & $\begin{array}{l}S \\
0.059\end{array}$ & $\begin{array}{l}\mathrm{Pb} \\
0.003\end{array}$ \\
\hline $\begin{array}{l}\text { Element } \\
\text { Mass content in \% }\end{array}$ & $\begin{array}{l}\mathrm{Si} \\
0.27\end{array}$ & $\begin{array}{l}\mathrm{Ni} \\
0.10\end{array}$ & $\begin{array}{l}\text { Mo } \\
0.13\end{array}$ & $\begin{array}{l}\mathrm{Nb} \\
0.003\end{array}$ & $\begin{array}{l}\mathrm{Fe} \\
\text { Balance }\end{array}$ \\
\hline
\end{tabular}

The data shown represent mean values obtained from various samples and have been recompiled from Holzweissig et al. ${ }^{9}$

gauge section during the experiment for DIC, a hightemperature extensometer measuring and controlling the longitudinal strain and a two-colour pyrometer controlling the temperature. For the phase transformation experiments two extensometers were used, which allowed for measuring the longitudinal and the transversal strain simultaneously. Images of the gauge section were recorded with a digital microscope during the phase transformation for DIC, and nozzles provided for a nitrogen atmosphere around the specimens in order to minimize oxidation. A two-colour pyrometer was used to control the temperature-time path and heating via direct current provided for a negligible temperature gradient within the gauge length.

In the low-cycle fatigue (LCF) experiments the test temperature was $550{ }^{\circ} \mathrm{C}$. All tests were conducted in strain control with a total strain amplitude of $0.35 \%$, a strain rate of $6 \times 10^{-3} \mathrm{~s}^{-1}$ and a R-ratio of -1 . The Inconel 939 specimens exhibited a coarse grained microstructure with a grain size of about $2 \mathrm{~mm}$. The images required for the DIC analysis were taken every 20 cycles at zero load from the same region of the gauge section where the EBSD measurement had been conducted prior to the experiment. Following the initial electropolishing, a thin oxide layer formed on the specimen surface during initial heating of the samples prior to the actual fatigue test. This oxide layer rapidly provided for stable speckle pattern, which could be used for the DIC analysis. The images for DIC were taken at a magnification of $100 \times$, whereby the image definition was 3200 pixel $\times 2400$ pixel. The subset, that is, the sub-image used to track the subset centre's displacement, was 80 pixel $\times 80$ pixel in size, and thus, substantially smaller than the grain size. After the displacement fields were determined, the strain fields were calculated in a post-processing operation utilizing a pointwise least square algorithm. The stepsize, that is, the distance the subset proceeds after the calculation of the previous subset, was 5 pixels.
In the phase transformation experiments, the specimens were heated to an austenitization temperature of $1200{ }^{\circ} \mathrm{C}$ within $15 \mathrm{~s}$ and were held at this temperature for $10 \mathrm{~s}$. Afterwards, the specimens were quenched by reduction of the direct current at a nominal rate of $70^{\circ} \mathrm{C} / \mathrm{s}$ to the isothermal bainitic phase transformation temperature of $340^{\circ} \mathrm{C}$ to obtain lower bainite. This cooling rate guaranteed that no unintended phase transformation took place before the isothermal transformation temperature was reached. Upon attaining the isothermal holding temperature yet prior to the onset of the phase transformation, a tensile stress of $50 \mathrm{MPa}$ was applied to the specimens. When stresses are superimposed to the bainitic phase transformations, transformation plasticity (TP) strains evolve which can determined by

$$
\varepsilon_{\mathrm{TP}}=\varepsilon_{\mathrm{l}}(\mathrm{t})-\Delta \mathrm{V} / 3 \mathrm{~V}(\mathrm{t}) \approx 2 / 3\left(\varepsilon_{\mathrm{l}}(\mathrm{t})-\varepsilon_{\mathrm{t}}(\mathrm{t})\right)
$$

where $\Delta \mathrm{V} / 3 \mathrm{~V}$ is the volume change, and $\varepsilon_{1}$ and $\varepsilon_{\mathrm{t}}$ represent the longitudinal and the transversal strain, respectively. The images for the DIC analysis were taken at a magnification of $250 \times$, where the image definition was 4800 pixel $\times 3600$ pixel. The images used for the DIC analysis were taken every $20 \mathrm{~s}$ after the isothermal holding temperature was attained. For the DIC analysis the subset was 60 pixel $\times 60$ pixel in size, which is in accord with the prior austenite grain size, and the stepsize was 4 pixels. Even though a nitrogen atmosphere was present around the specimens throughout the experiments, a thin oxide layer formed on the surface during austenitizing. Similar to the LCF tests, this oxide layer could be used as the speckle pattern for DIC since it remained unchanged during the subsequent phase transformation. After the experiment, EBSD measurements were carried out to correlate the strain obtained from the DIC analysis with the local microstructural features. However, the thin oxide layer had to be removed prior to the EBSD measurements, as EBSD probes about a few hundred nanometres at the surface only. Thus, electropolishing time was reduced to a minimum in order 


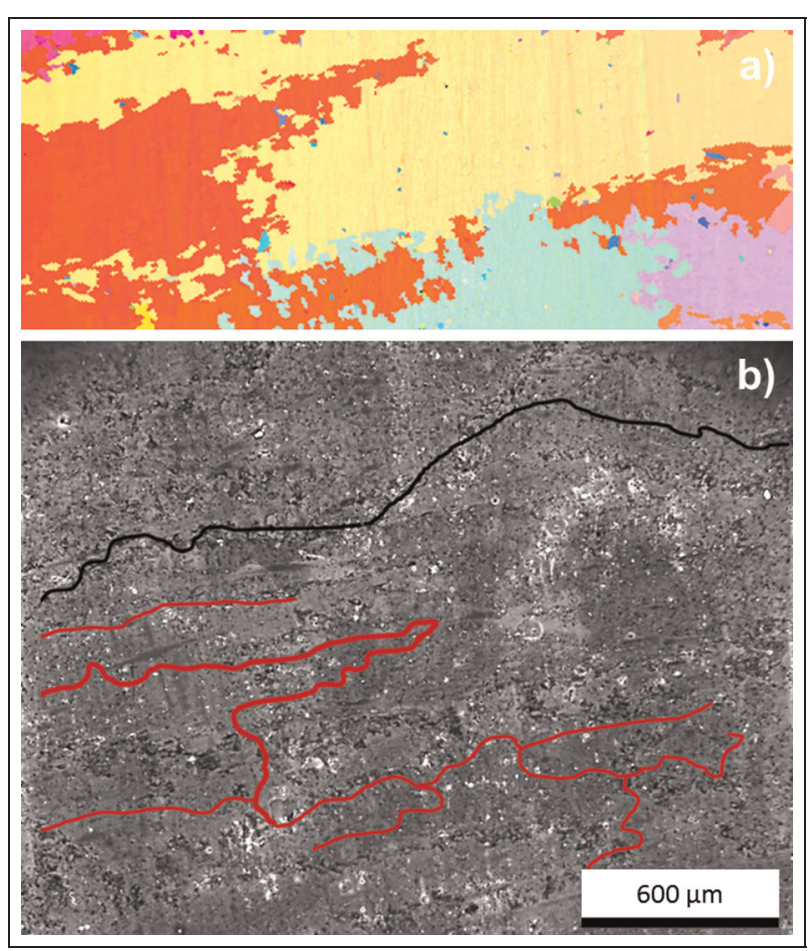

Figure 2. (a) EBSD orientation map measured at the gauge section of the fatigue specimen made of Inconel 939. A digital microscope image of the area scanned by EBSD is shown in (b) The grain boundaries detected in the corresponding EBSD measurements are highlighted in red. The path of fatigue crack is marked in black.

to remove the oxide layer, but leave the underlying material nearly unaffected. As shown later on, there is a trade-off as more material removal will improve EBSD image quality, but some of finer microstructural feature will get lost at the same time.

\section{Results and discussion}

\section{High-temperature fatigue}

An EBSD orientation map of an undeformed Inconel specimen taken prior to the high-temperature fatigue experiment is shown in Figure 2(a). The grain boundaries detected in the EBSD measurement are superimposed on the digital microscope image taken from the gauge section of the specimen (Figure 2(b)) and the crack path observed in the failed specimen is highlighted in black.

An immediate observation made during the LCF experiments is that the crack path can be predicted at an early stage from the DIC results in Figure 3 as high von-Mises strains start to become obvious in some areas at around half fatigue life. In Figure 3 the crack propagated from the upper right to the left side. Locally, elevated von-Mises strains could be detected already at 7000 cycles. The ensuing crack path is again marked by the increasing local strain magnitudes after 10,000 and 14,000 cycles, and finally the elevated local strains delineate the crack path when the specimen failed at 14,650 cycles. Interestingly, there are no significantly elevated strains present at the grain boundaries as seen in Figure 3; however, the crack did bypass the region scanned by EBSD. Currently, it is not clear what the microstructural reason for the increased local strains is. It might well be that in this material a subsurface feature might constitute a weak link within the microstructure that could have been the initial point for damage. ${ }^{2,10-12}$ In the literature, ${ }^{12-15}$ it is often described that dendrites are the initial point for damage evolution. It should be noted, however, that the locally high vonMises strains did not perfectly match the dendrite structures. Currently, a clear evidence for the decisive role of dendrites in the investigated material is thus missing, and further studies are needed to address this issue.

\section{Bainitic transformation}

The phase transformation experiments carried out on the low alloy tool steel revealed that under a superimposed load of $50 \mathrm{MPa}$, a strain localization took place for both the longitudinal and the transversal strain component. Yet the mean value of the longitudinal strain component determined by DIC was higher than the mean value of the transversal strain component (see Figure 4). The local TP strains calculated using equation (1) are illustrated in Figure 5. The TP strains are attributed to different mechanisms in literature, and one of these is bainite variant selection due to the superimposed stress present during the phase transformation. ${ }^{8,16-21}$

The presence of variant selection during the austenite-to-bainite phase transformation can be evidenced by a direct comparison between the DIC and the EBSD results (see Figure 6). The area marked with a white rectangle in Figure 5 was scanned by EBSD. The DIC results within the rectangle are magnified and cropped from Figure 5 in order to allow for a direct comparison between DIC and EBSD. The areas exhibiting the highest microscopic TP values are encircled in both images. Most of these zones feature only a small number of variants, which results in high TP strains. ${ }^{8,22}$ The EBSD orientation map reveals that in the areas with high TP strains the variants are preferably oriented along the [101], [201] and [121] orientations. In the zones with small or near-zero TP strains, a larger number of variants had nucleated and there is more frequent interaction of the variants with each other. It should be noted that the TP strain fields in the DIC images and the variants detected in the EBSD orientation maps do not always perfectly fit. This can be attributed to two effects. First, some of the material had to be removed by electropolishing in order to obtain a surface quality good enough for the EBSD measurement. Material removal by electropolishing was calibrated on companion specimens and for the conditions employed approximately $10 \mu \mathrm{m}$ was taken off. Thus, a good correlation between EBSD and DIC can only be expected if larger groups of similarly 


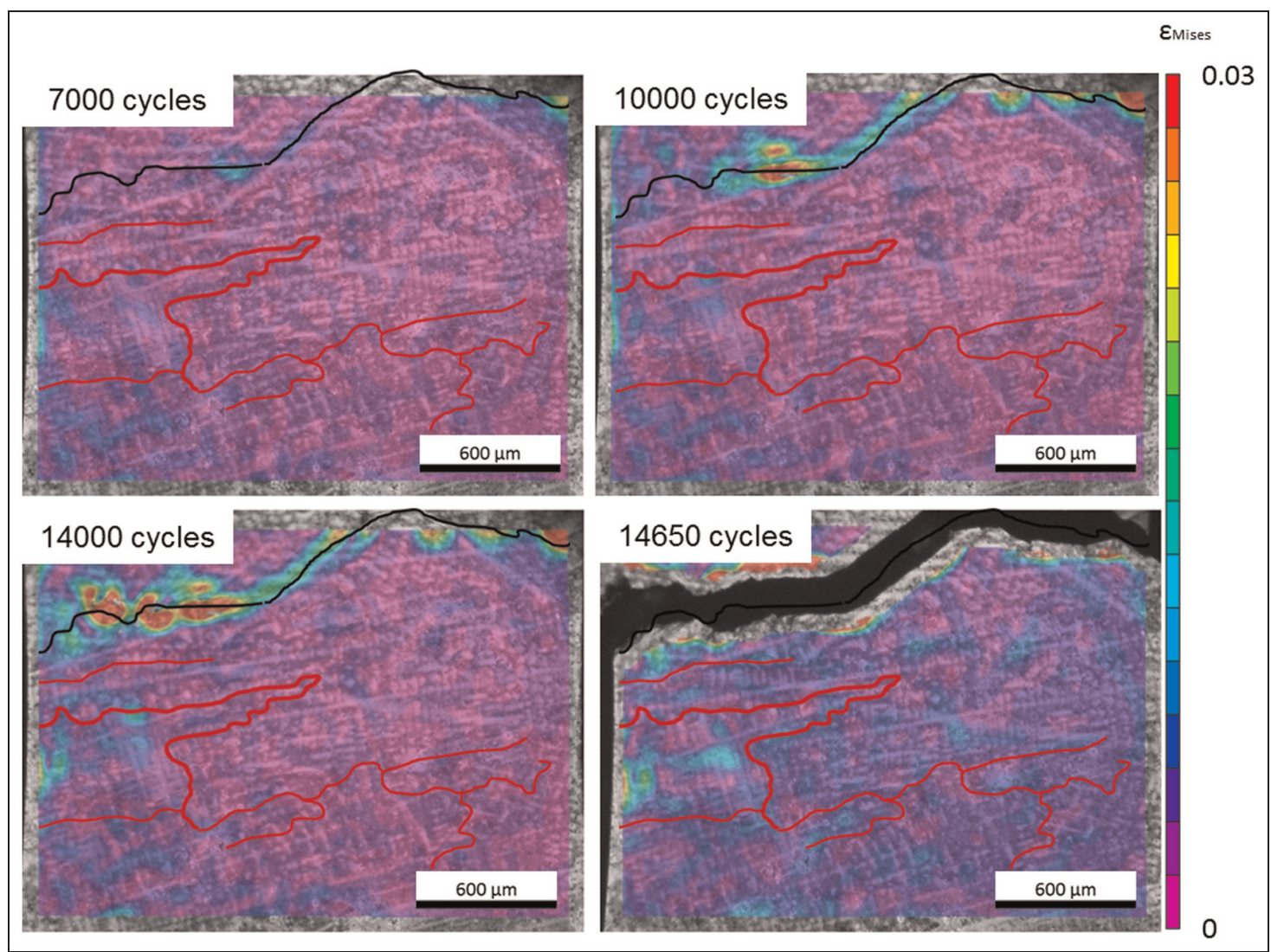

Figure 3. DIC images demonstrating the von-Mises strains at the surface of a specimen made of Inconel 939 at zero load. The specimen was fatigued under a strain amplitude of $0.35 \%$ and a R-ratio of $-\mathrm{I}$ at a temperature of $550{ }^{\circ} \mathrm{C}$. The grain boundaries detected in the EBSD measurement prior to the experiments are highlighted in red. The crack path in the gauge section is traced in black.

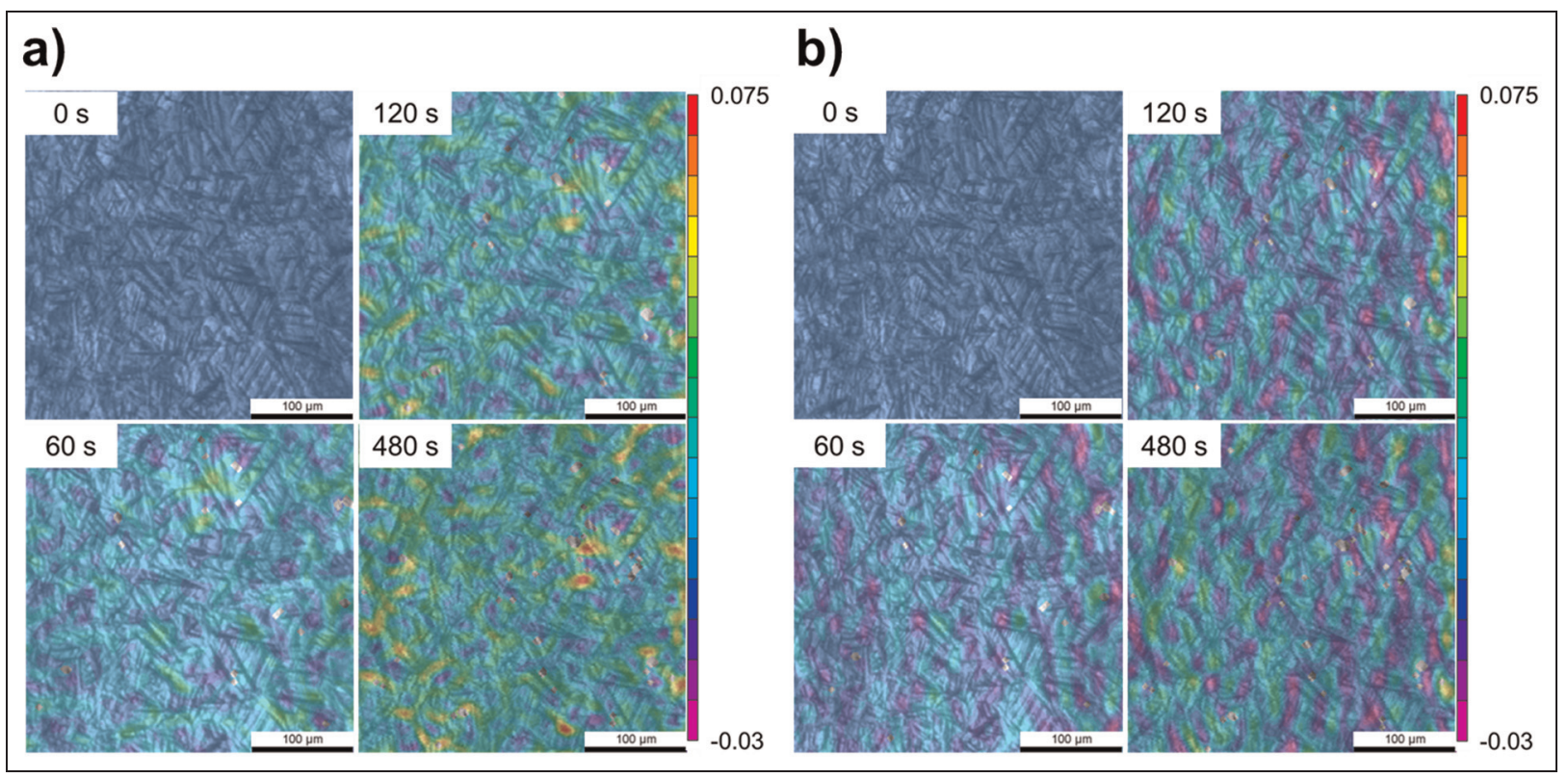

Figure 4. DIC images demonstrating the evolution of (a) longitudinal and (b) transversal strains during an isothermal bainitic phase transformation at $340^{\circ} \mathrm{C}$ under $50 \mathrm{MPa}$ superimposed stress following an austenitization treatment at $1200^{\circ} \mathrm{C}$ for $10 \mathrm{~s}$.

oriented bainite exist in a surface layer thicker than what was removed during electropolishing. In Figure 6(a), this is most obvious at the right-hand side of the image. Second, DIC cannot yet resolve strains with a resolution good enough to resolve the contribution of individual bainite variants, and thus, DIC strains will better fit theoretical strains for a larger group of similarly oriented bainite variants. 


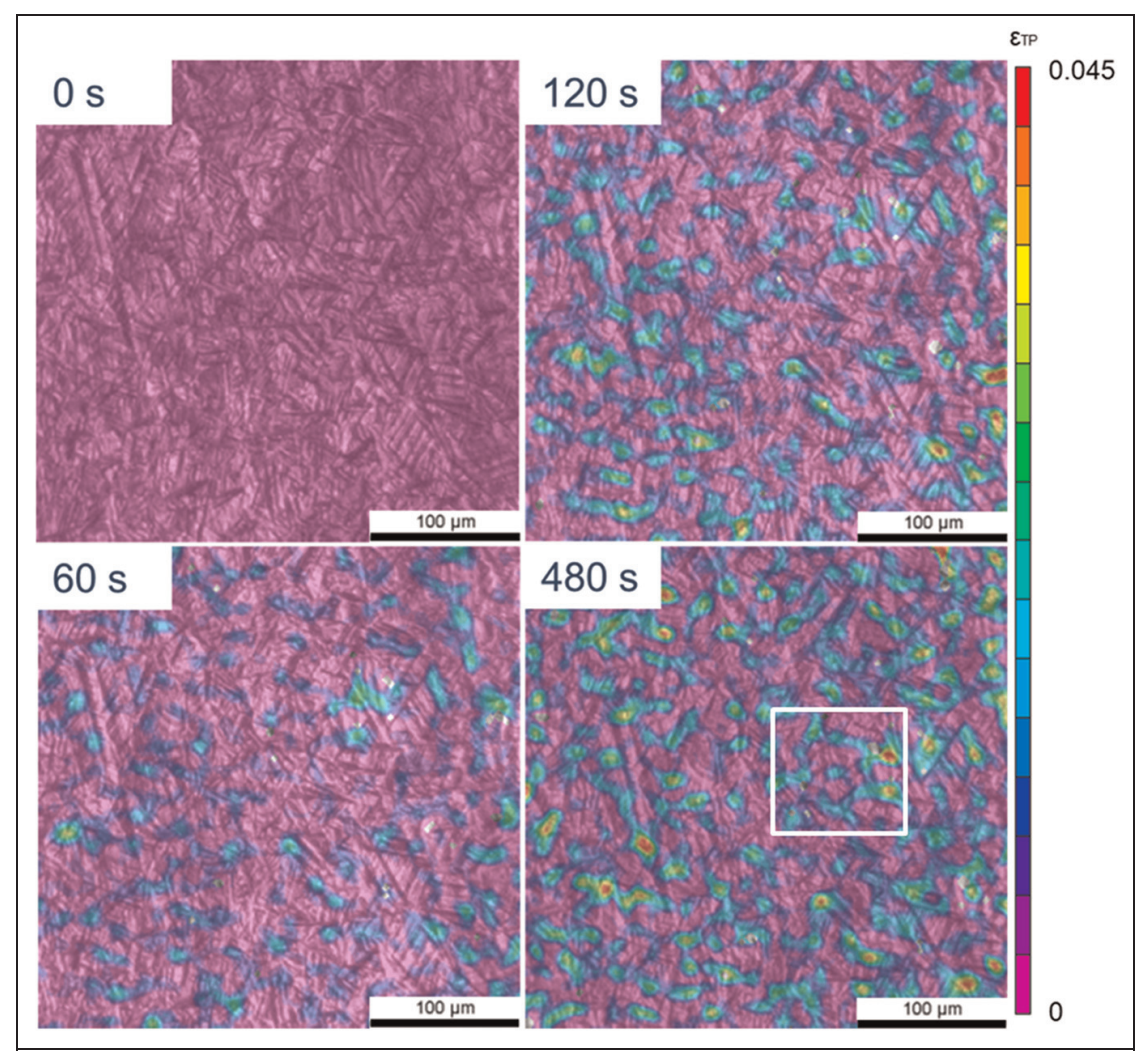

Figure 5. DIC images demonstrating the evolution of TP strains during an isothermal bainitic phase transformation (same conditions as in Figure 4). The area marked in the image taken at $480 \mathrm{~s}$ was scanned by EBSD (cf. Figure 6 ). The data have partially been recompiled from Holzweissig et al. ${ }^{9}$

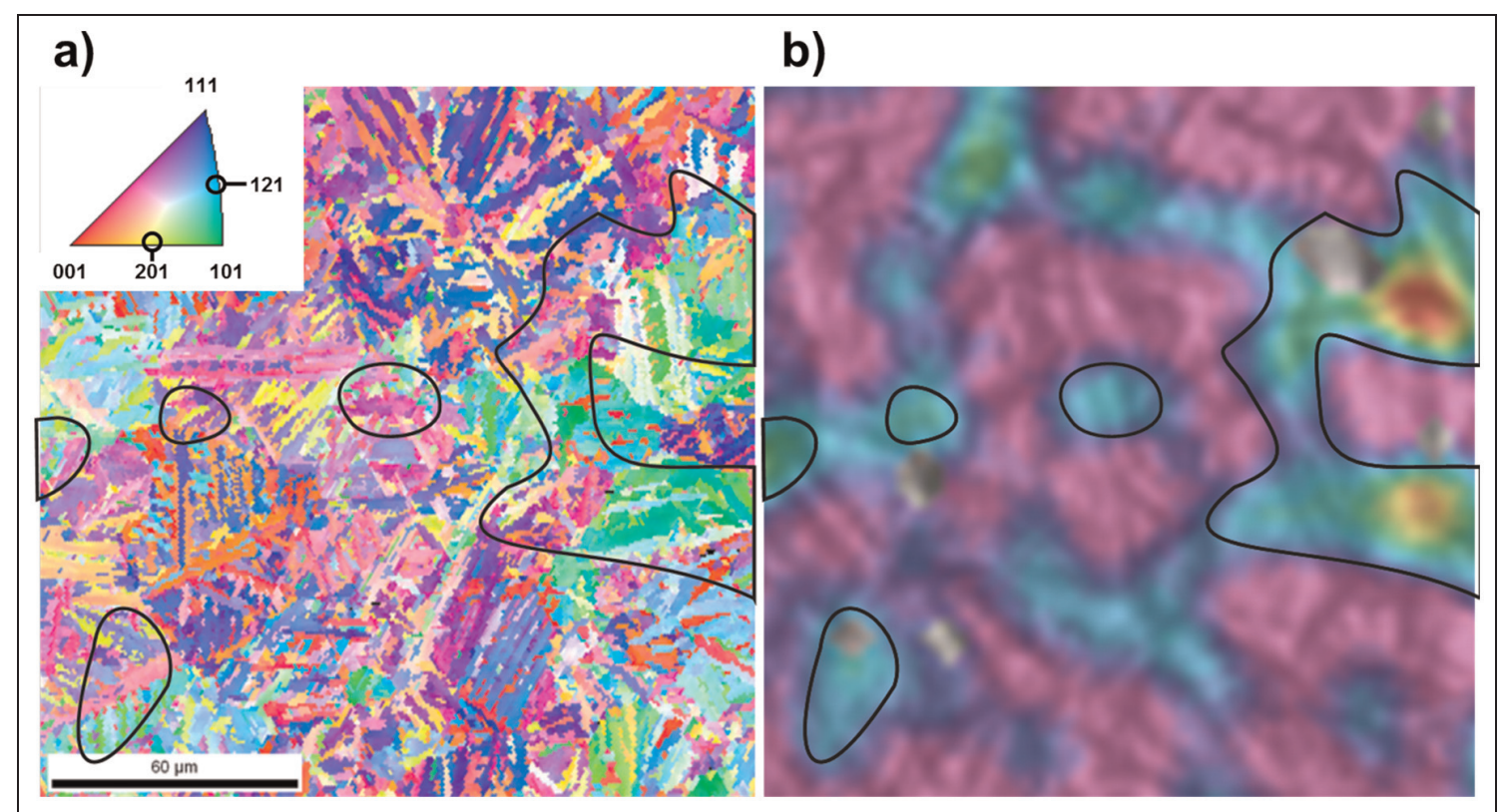

Figure 6. (a) EBSD orientation map of the specimen isothermally transformed to bainite. The area shown corresponds to the marked rectangular region of the surface analysed with DIC in Figure 5, which has been enlarged in (b). The encircled zones in both images demonstrate the near one-to-one correspondence of the variant orientations and TP strains.

\section{Validation of data}

Validation of the strains computed by DIC is often a key issue. In this study, the DIC strain results were averaged over the imaged area and then compared with the macroscopic strains measured simultaneously by an extensometer. In case of the high-temperature LCF experiments on the nickel-based Inconel 939 alloy, both the averaged DIC strains and the data from the 


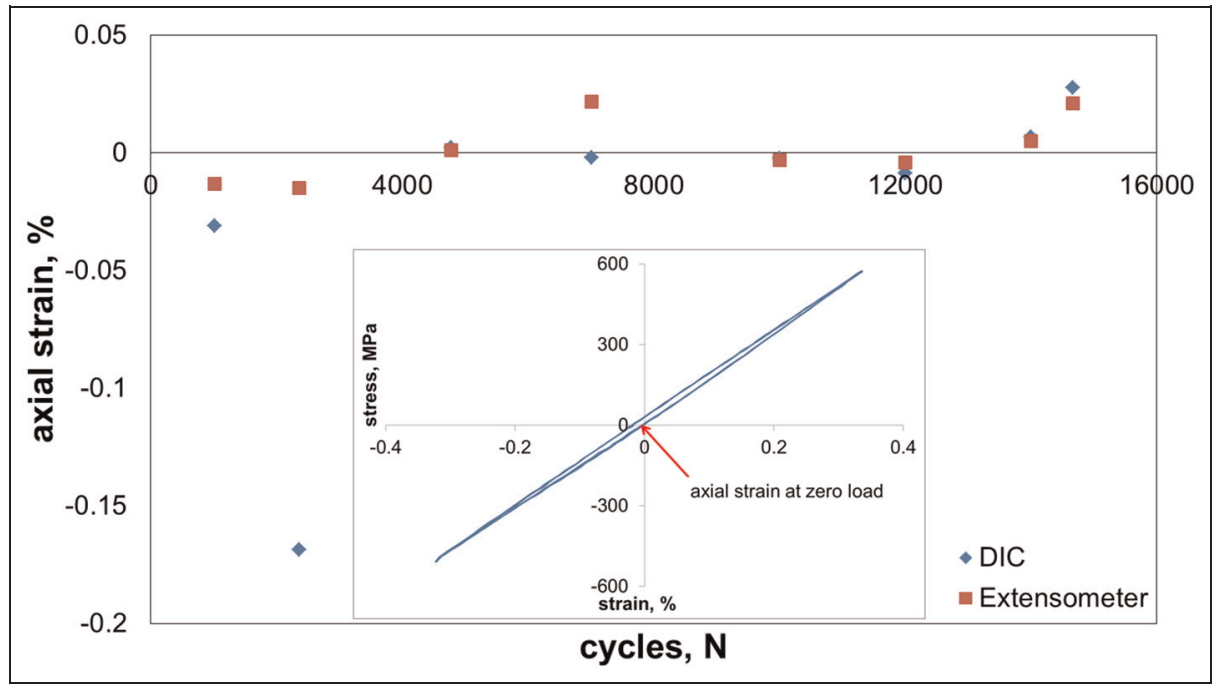

Figure 7. Evolution of residual axial strains with cycles measured by DIC and extensometer. For measuring the residual strains, the fatigue experiment was stopped and the external load was reduced to $0 \mathrm{~N}$.

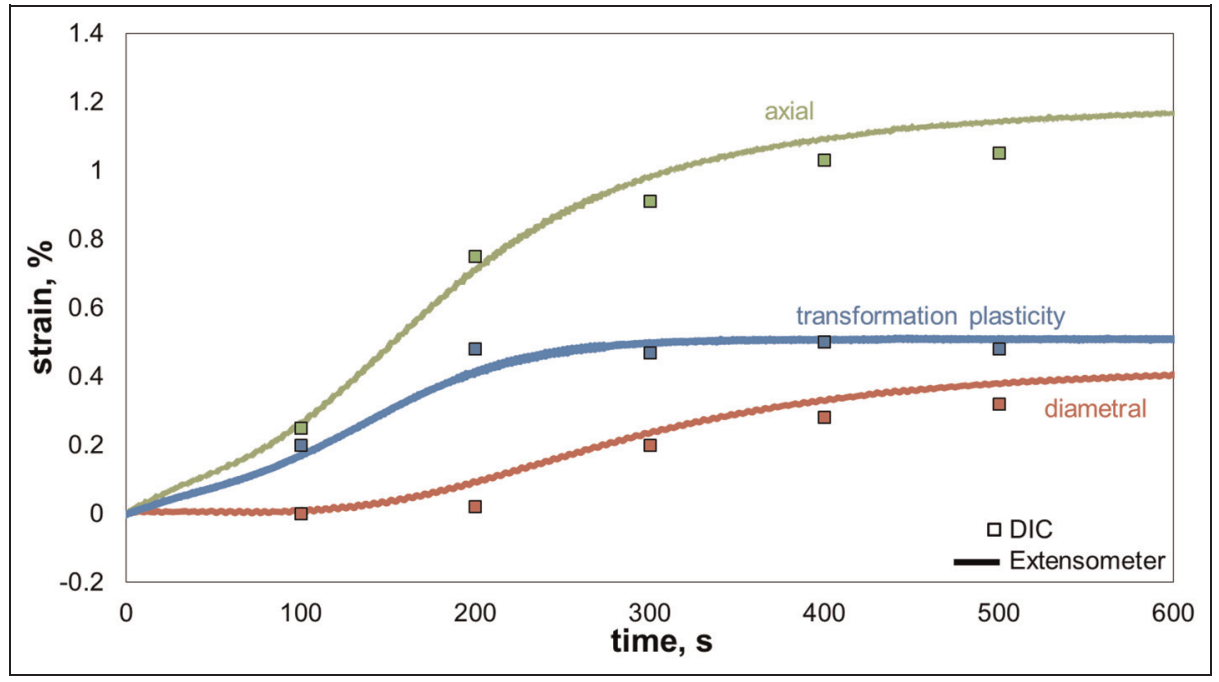

Figure 8. Evolution of axial, diametral and transformation plasticity strains with time for an isothermal bainitic phase transformation at $340^{\circ} \mathrm{C}$ under $50 \mathrm{MPa}$ superimposed stress following an austenitization treatment at $1200^{\circ} \mathrm{C}$ for $10 \mathrm{~s}$. The data obtained by extensometry are illustrated as lines (partially recompiled from Holzweissig et al. ${ }^{9}$ ) and open squares depict DIC data.

extensometry were close to each other except for one case (Figure 7). The strain data shown in Figure 7 were recorded at zero load. Near the end of fatigue life both the data from the extensometer and the DIC analysis can get affected by crack growth, but not necessarily to the same extent. Similarly, the averaged DIC data correspond to a much smaller area than what is probed by the extensometer, and effects such as temperature gradients will not equally contribute to both data sets.

A similar approach was used for the validation of the DIC data in the phase transformation experiments. In this case, however, both the evolution of longitudinal and transversal strains was tracked by conventional extensometers (see Figure 8). The comparison of the strain values measured by DIC averaged over the imaged section and extensometers revealed that the values correspond very well to each other within a maximum deviation of $\pm 0.2 \%$. Again, this is a result of the difference in temperature gradients. In this case, the DIC was averaged at a central position within the gauge section over an area with dimensions of about $350 \mu \mathrm{m} \times 350 \mu \mathrm{m}$. By contrast, the longitudinal and transversal extensometers averaged strain a much greater area, namely, $12 \mathrm{~mm} \times 1 \mathrm{~mm}$ for the longitudinal and $10 \mathrm{~mm} \times 1 \mathrm{~mm}$ for the transversal component, due to gauge length of the extensometers used. The good agreement between the two data sets indicates that the temperature gradient in the gauge length was quite small, as expected for direct current heating. 


\section{Conclusion}

The current work was undertaken with the motivation of combining DIC with EBSD in order to correlate local strain measurement with the relevant microstructural features. A series of high-temperature LCF experiments on Inconel 939 and phase transformation experiments on low alloy tool steel $40 \mathrm{CrMnMoS} 86$ were conducted in order to assess the potential and the limitations of the approach. The results of this study can be summarized as follows:

- Provided that the environmental conditions are such that a sufficiently stable oxide layer forms on metal-based materials, the oxide can provide for enough contrast to be used as speckle pattern for DIC.

- In the high-temperature LCF experiments, a localization of von-Mises strains could be detected at an early stage of fatigue life.

- In the phase transformation experiments, a variant selection active during the stress-assisted austeniteto-bainite phase transformation could be detected. Particularly, the combined DIC and EBSD experiments revealed that the growth of [101], [201] and [121] variants yield high local TP strains.

- For validation of the strain data obtained in the high-temperature experiments, DIC strain values were averaged over the area imaged and compared to macroscopic strain values obtained by conventional extensometry. In both types of experiments a good correlation of the strain values was obtained. The strain differences are mainly a result of the locally varying temperature gradients.

\section{Declaration of conflicting interests}

The authors declare that there is no conflict of interest.

\section{Funding}

This work was financially supported by Deutsche Forschungsgemeinschaft within the Transregional Collaborative Research Center TRR 30 'Prozessintegrierte Herstellung funktional gradierter Strukturen auf der Grundlage thermo-mechanisch gekoppelter Phänomene'.

\section{References}

1. Efstathiou $\mathrm{C}$ and Sehitoglu H.Strain hardening and heterogeneous deformation during twinning in Hadfield steel. Acta Mater 2010; 58: 1479-1488.

2. Davidov A, Jain MK, Petrov RH, et al. Strain localization and damage development during bending of Al-Mg alloy sheets. Mater Sci Eng A 2012; 550: 395-407.

3. Niendorf T, Lackmann J, Gorny B, et al. In situ characterization of martensite variant formation in nickeltitanium shape memory alloy under biaxial loading. Scripta Mater 2011; 65: 915-918.
4. Pan B, Wu D, Wang Z, et al. High-temperature digital image correlation method for full-field deformation measurement at $1200^{\circ}$ C. Meas Sci Technol 2011; 22: 015701.

5. Niendorf T, Burs C, Canadinc D, et al. Early detection of crack initiation sites in TiAl alloys during low-cycle fatigue at high temperatures utilizing digital image correlation. Int J Mater Res 2009; 4: 603-608.

6. Grant BMB, Stone HJ, Withers PJ, et al. High-temperature strain field measurement using digital image correlation. J Strain Anal Eng 2009; 44: 263-271.

7. Niendorf T, Dadda J, Canadinc D, et al. Monitoring the fatigue-induced damage evolution in ultrafine-grained interstitial-free steel utilizing digital image correlation. Mater Sci Eng A 2009; 517: 225-234.

8. Lackmann J, Niendorf T, Maxisch M, et al. High-resolution in-situ characterization of the surface evolution of a polycrystalline NiTi SMA-alloy under pseudoelastic deformation. Mater Charact 2011; 62: 298-303.

9. Holzweissig MJ, Canadinc D and Maier HJ.In-situ characterization of transformation plasticity during an isothermal austenite-to-bainite phase transformation. Mater Charact 2012; 65: 100-108.

10. Rudnicki JW and Rice JR.Conditions for the localization of deformation in pressure-sensitive dilatant materials. J Mech Phys Solids 1975; 23: 597-605.

11. Tomkins B.Fatigue crack propagation - an analysis. Philos Mag 1968; 18: 1041.

12. Miskovic Z, Jovanovic M, Gligic M, et al. Microstructural investigation of IN 939 superalloy. Vacuum 1992; 43: 709-711.

13. Gambone ML, Shendye SB, Andrews P, et al. Properties of RS5 and other superalloys cast using thermally controlled soldification. In: TM Pollock, RD Kissinger, RR Bowman, et al. (eds), Superalloys 2000, Warrendale, PA, USA, 17-21 September 2000, pp. 161-170.

14. Biallas $\mathrm{G}$ and Maier HJ.In-situ fatigue in an environmental scanning electron microscope - potential and current limitations. Int J Fat 2007; 29: 1413-1425.

15. Li F, Li S, Wu Y, et al. Thermal cycle fatigue behaviors of a single crystal $\mathrm{Ni}_{3} \mathrm{Al}$ base alloy. Procedia Eng 2012; 27: 1141-1149.

16. Magee CL.Transformation kinetics, microplasticity and aging of martensite in $\mathrm{Fe}-31 \mathrm{Ni}$. PhD Thesis, Carnegie Mellon University, Pittsburgh, PA, 1966.

17. Taleb L and Petit S.New investigations on transformation induced plasticity and its interaction with classical plasticity. Int J Plast 2006; 22: 110-130.

18. Shipway PH and Bhadeshia HKDH. The effect of small stresses on the kinetics of the bainite transformation. Mater Sci Eng A 2010; 201: 143-149.

19. Lambers H-G, Tschumak S, Maier HJ, et al. Evolution of transformation plasticity during bainitic transformation. Int J Mater Res 2011; 102: 1152-1163.

20. Kundu S, Hase K and Bhadeshia HKDH. Crystallographic texture of stress affected bainite. Philos T Roy Soc A 2007; 463: 2309-2328.

21. Bhadeshia HKDH. Bainite in steels. 2nd ed.Cambridge: Cambridge University Press, 2001.

22. Holzweissig MJ, Canadinc D and Maier HJ.In situ characterization of backstress effects on the austenite-tobainite phase transformation. Scripta Mater 2012; 67: 368-371. 